\title{
REFLEXÕES SOBRE MÉTODOS QUALITATIVOS DE PESQUISA EM ENFERMAGEM
}

\author{
Magda Andrade Rezende* \\ Mara Regina Rosa Ribeiro* \\ Maria Geralda Gomes Aguiar"*
}

REZENDE, M. A.; RIBEIRO, M. R. R; AGUIAR, M. G. G. Reflexठes sobre métodos qualitativos de pesquisa em Enfermagem. Rev. Esc. Enf. USP, v. 26, n. 3, p. ～～， dez., 1992.

Este ensaio traz consideraçōes sobre métodos quantitativos e qualitativos de pesquisa em Enfermagem Aborda suas especificidades, faz uma distinģđo entre método e técnica, e da ênfase aos pressupostos epistemologicos que embasam o método.

UNITERMOS: Pesquisa em enfermagem. Métodos de pesquisa. Pesquisa qualitativa

\section{Introduçáo}

Neste trabalho estamos nos propondo a fazer algumas reflexões sobre os métodos qualitativos de pesquisa em enfermagem. Isso se deve ao fato de que métodos qualitativos vêm sendo cada vez mais utilizados por enfermeiros nos Estados Unidos e no Brasil (LEININGER, 1985; KAMIYAMA, 1988; PIERIN et al, 1989; STEFANELLI et al 1990), originando em nosso meio uma série de questőes como: no que consistem, qual sua especificidade, se podem ser usados em nossa profissão e outras.

Talvez nossas reflexões contenham mais perguntas do que respostas, mas provavelmente, isto é o reflexo do momento que estamos vivendo - da entrada em contato com diferentes métodos de pesquisa.

Ao pensarmos no uso de métodos qualitativos em pesquisas realizadas por enfermeiros perguntamo-nos: por que deveriam ser usados, os quantitativos não bastam? Parece-nos que a resposta é, claramente, "não". Apesar de poderem dar respostas satisfatórias para uma série de questões, os métodos quantitativos não esgotam nossa compreensão a respeito dos eventuais problemas sobre os quais nos debruçamos em nossa prática cotidiana.

- Mestre em Enfermagem. Assistente junto à disciplina Enfermagem Pediátrica do Departamento de Enfermagem Materno-Infantil e Psiquiatrica da Escola de Enfermagem da USP.

* Auxiliar de Ensino da disciplina de Enfermagem Materno-Infantil do Departamento de Enfermagem da Universidade Federal de Mato Grosso. Aluna do programa de Pós-Graduaçāo, nfvel de Mestrado da EEUSP, área de concentração de Enfermagem Pediátrica.

* * Assistente de Ensino da disciplina de Enfermagem Psiquiátrica da Universidade Estadual do Sudoeste da Bahia, Campus de Jequié. Aluna do programa de Pós-Graduação, nfvel de Mestrado da EEUSP, área de concentraçấo de Enfermagem Psiquiátrica. 
Os métodos qualitativos de pesquisa são úteis para nós, enfermeiros, porque podem contribuir para a compreensão de facetas do nosso objeto de estudo, que não podem ser adequadamente apreendidas pelos métodos quantitativos. Isso porque buscam compreender fenరmenos como emoçáo, significado e percepçăo, sob o ponto de vista dos informantes. $O$ uso de métodos qualitativos pode ser útil, inclusive, para maior compreensăo de nossa profissáo e de suas particularidades. Veja-se, por exemplo, estudo realizado por ANGELO (1989) com alunos do curso de graduação em Enfermagem, no qual foi possível caracterizar sua percepção sobre as docentes e o processo de ensino-aprendizagem.

Buscamos, então, conhecer as características dos métodos, partindo dos pesquisadores que deles se utilizam, e constatamos ser esta tarefa um tanto árdua, pois é diversificado o entendimento de cada autor quanto ao que é método. Acreditamos que isto ocorre, na Enfermagem, devido à insuficiente compreensáo do método enquanto pressuposto epistemológico e enquanto procedimento técnico.

É possivel entender o porquê da confusăo entre método e técnica, tendo em vista que ainda predomina a ideologia do paradigma dominante (positivista), a qual entende que o conhecimento só pode ser obtido por meios que garantam neutralidade e possibilidade de replicação. Deste modo, o pesquisador pode, ao se utilizar de métodos qualitativos, fazê-lo através dos "oculos" do quantitativo, usando critérios cabíveis neste e não naquele. Em tal situação, evidentemente, o método se reduzirá à sua face técnica, ao seu "modo de fazer".

No entanto, pensamos que a técnica pode ser separada do método, embora, por si so, não tenha vida própria, a qual lhe é dada pelos pressupostos epistemológicos que embasam o método. A postura epistemológica do autor modifica a técnica, embora mantendo-lhe a forma primitiva. Podemos exemplificar o emprego de técnica com outros pressupostos, que não aqueles originalmente concebidos para seu uso, através dos comentários de THIOLLENT (1980), sobre a enquete operária. Esta foi concebida por MARX no final do século passado. Seu pressuposto epistemologico se fez presente na sua forma de conceber a enquete, a qual foi organizada por indagaçôes encadeadas umas às outras, que ao enfatizar respostas de cunho cognitivo, tinha por fim desencadear no informante, um processo de reflexão a respeito da realidade. Portanto, era uma concepção muito diferente da usual, que preconizava perguntas pretensamente neutras e pouco articuladas umas com as outras. No caso do trabalho de MARX, a enquete continuou a ser uma enquete, apesar de embebida por um pressuposto filosófico complementar diferente daquele para o qual havia sido originalmente elaborada.

Acreditamos que o pesquisador deve ter um sólido conhecimento sobre epistemologia, bem como sobre métodos e técnicas, a fim de que suas escolhas sejam conscientes e apropriadas ao fenómeno que busca conhecer.

Continuando na tentativa de compreender a especificidade dos métodos qualitativos e quantitativos, tomamos MANNHEIM (1972) como referência, devido a sua importante influência no campo da teoria do conhecimento. Para ele, o modo de obtenção do conhecimento é determinado pelo momento histórico vivido: "em tempos em que a visão de mundo objetiva permanece mais ou menos inabalada, e nas épocas que conseguem apresentar uma ordenação de mundo inambiguamente perceptível, existe a tendência a basear nos fatores objetivos a existencia do sujeito humano conhecedor e de suas capacidades intelectuais". Assim, para MANNHEIM (1972), a tendência de se entender o mundo, centrando 
o conhecimento no proprio objeto a ser conhecido deriva do pensamento medieval, via correntes racionalista francesa e alemã.

O paradigma que é caracterizado por MANNHEIM (1972) como: centrado no objeto a ser conhecido, generalizador e utilizador da atomização como método de estudo, por excelência, no nosso entender, pode ser identificado como parte do cerne dos métodos quantitativos.

A perda da hegemonia dessa visáo de mundo centrada no objeto, ocorrida com o Renascimento, deslocou para o sujeito o foco da obtençăo do saber. Esta corrente, que MANNHEIM (1972) chama de psicologia ontologica (por ter como centro o sujeito e por querer compreender o pensamento desde sua mais primitiva origem), tem como características: centrar-se no sujeito que está conhecendo o objeto, buscar o significado do fato para o sujeito, e se utilizar da interdependência entre as várias partes do que está sendo conhecido. Podemos correlacionar os pressupostos da psicologia ontológica, como parte do cerne dos métodos qualitativos.

Percebemos que o ponto de vista de SMITH e HESHUSIUS (1986) poderia completar o quadro descrito até aqui, adicionando características que formariam uma saudável distinçăo entre os métodos. Para eles, o quantitativo aspira a certeza e suas proposiçōes são prescritivas, visando criar um processo que se for adequadamente seguido, terá como produto algo que é um "retrato da realidade". O qualitativo, como nåo aspira a certeza, e sim a compreender uma determinada interpretação de um sujeito, não pode ser prescritivivo como o outro, e não tem tecnicas privilegiadas epistemologicamente.

Trazendo essa reflexāo para o âmbito da enfermagem, pensamos num primeiro momento, que a discussão sobre o uso de métodos qualitativos e quantitativos, esbarra na inexistência de conhecimento corrente sobre a importância da explicitação dos pressupostos epistemológicos do pesquisador. Esta não explicitação, no nosso entender, é um dos fatores que desencadeia e mantém a distância entre o discurso dos enfermeiros e sua prática. MUNHALL (1982), ao analisar a oposição entre a filosofia da Enfermagem e a de suas pesquisadas, percebe a clara identificação que se pode fazer da primeira, que se auto-denomina "individualizadora, holista, relativista", num flagrante confronto com a filosofia permeada através da maioria das pesquisas da área, predominantemente generalizadoras, reducionistas e categorizadoras.

Observa-se também essa dicotomia na maioria das disciplinas de Metodologia da Pesquisa dos Cursos de Pós-Graduação do país, nos quais se aborda o* método enquanto técnica/procedimento, sem enfocar a necessária discussão epistemológica (FRANCO, 1988), o que seguramente, acarreta prejuízos aos pesquisadores, sobretudo aos iniciantes.

Pensamos que a Enfermagem se propõe e quer ser humanista, mas năo consegue. Esse fosso que separa a Enfermagem proposta da real, parece estar aumentando cada vez mais, tanto por condições educacionais, sociais e económicas do nosso pais, como pela dificuldade dos enfermeiros em integrar as diferentes "partes" do saber já disponíveis, a serviço daquele que, enfim, e sua finalidade de existir: o cliente, o paciente. 
REZENDE, M.A.; RIBEIRO, M.R.R.; AGUIAR, M.G.G. Reflections about qualitative research methods in nursing research. Rev. Esc. Enf. USP, v. 26, n. 3, p. ～- , dec., 1992.

This essay brings considerations about quantitative and qualitative research methods in Nursing. It boards the quantitative and qualitative methods specifications, makes the distinction between method and technique, and gives emphasis to the episthemological pressuppositions which gives basis to the method.

UNITERMS: Nursing research. Research methods. Qualitative research.

\section{REFERENCIAS BIBLIOGRÁFICAS}

ANGELO, M. Vivendo uma prova de fogo: as experiencias inciais de alunas de enfermagem. Såo Paulo, 1989. 144p. Tese (Doutorado) - Instituto de Psicologia, Universidade de São Paulo.

FRANCO, M.L.P.B. Porque o conflito entre tendencias metodologicas não e falso. Cad. Pesq., n. 66, p. 75-80, 1988.

KAMIYAMA, Y. Apresentaçăo In: ENCONTRO INTERAMERICANO DE PESQUISA QUALITATIVA EM ENFERMAGEM, 1, São Paulo, 1988. Resumos. São Paulo, EEUSP/UFSC, 1988. p. 7-8.

LEININGER, M. M. Qualitative research methods in nursing. London, GRUNER \& STRATON, 1985. cap. 1, p. 1-25: Nature, rationale and importance of qualitative research methods in nursing.

MANNHEIN, K. Ideologia e utopia. Rio de Janeiro, Zahar, 1972. p. 29: Abordagem preliminar do problema.

MUNHALL, P.L. Nursing philosophy and nursing research: in apposition or opposition? Nurs. Res. v. 31, n. 3, p. 176-7, 181, 1982.

PIERIN, A.M.G. et al. Perspectivas da pesquisa qualitativa para a enfermagem. Acta Paul. Enf., v. 2, n. 3, p.86-9, 1989.

SMITH, J.K; HESHUSIUS, L. Closing down the conversation the end of the quantitative-qualitative debate. Educ. Res, v. 14, n. 1, p. 1-12, 1986.

STEFANELLI, M.C. et al. Situação da pesquisa qualitativa em enfermagem no Brasil. Rev. Paul. Enf., v.9, n. 2, p.5-6, 1990.

THIOLLENT, M. Crítica metodológica, investigação social e enquete operăia. São Paulo, Polis, 1980. cap. 4, p. 101-26: Sobre a enquete operária. 